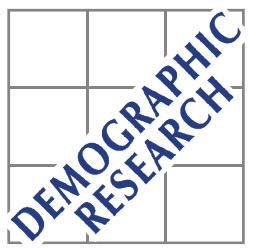

Demographic Research a free, expedited, online journal of peer-reviewed research and commentary in the population sciences published by the Max Planck Institute for Demographic Research Konrad-Zuse Str. 1, D-18057 Rostock · GERMANY www.demographic-research.org

DEMOGRAPHIC RESEARCH

VOLUME 23, ARTICLE 5, PAGES 105-116 PUBLISHED 16 JULY 2010

http://www.demographic-research.org/Volumes/Vol23/5/

DOI: $10.4054 /$ DemRes.2010.23.5

Descriptive Findings

\title{
The association between resilience and survival among Chinese elderly
}

Ke Shen

Yi Zeng

(C) 2010 Ke Shen \& Yi Zeng.

This open-access work is published under the terms of the Creative Commons Attribution NonCommercial License 2.0 Germany, which permits use, reproduction \& distribution in any medium for non-commercial purposes, provided the original author(s) and source are given credit. See http:// creativecommons.org/licenses/by-nc/2.0/de/ 


\section{Table of Contents}

1 Introduction 106

2 Data and measurements 106

3 Methods 109

$4 \quad$ Results 109

$5 \quad$ Discussion and conclusions $\quad 111$

6 Acknowledgements 113

$\begin{array}{ll}\text { References } & 114\end{array}$ 


\title{
The association between resilience and survival among Chinese elderly
}

\author{
Ke Shen ${ }^{1}$ \\ Yi Zeng ${ }^{2}$
}

\begin{abstract}
Based on the unique longitudinal data of the elderly aged 65+ with a sufficiently large sub-sample of the oldest-old aged 85+ from the Chinese Longitudinal Healthy Longevity Survey, we construct a resilience scale with 7 indicators for the Chinese elderly, based on the framework of the Connor-Davidson Resilience Scale. Cox proportional hazards regression model estimates show that, after controlling for sociodemographic characteristics and initial health status, the total resilience score and most factors of the resilience scale are significantly associated with reduced mortality risk among the young-old and oldest-old. Although the causal mechanisms remain to be investigated, effective measures to promote resilience are likely to have a positive effect on longevity of the elderly in China.
\end{abstract}

\footnotetext{
${ }^{1}$ Ph.D. candidate, China Center for Economic Research, National School of Development at Peking University.

${ }^{2}$ Corresponding author: Professor, Center for the Study of Aging and Human Development, Geriatric Division of Medical School, Duke University; China Center for Economic Research, National School of Development at Peking University; and Distinguished Research Scholar at Max Planck Institute for Demographic Research. Mailing address: Box 3003, Duke University, Durham, NC 27710, U.S.A. E-mail: zengyi68@gmail.com.
} 


\section{Introduction}

Resilience, a psychological construct, has been defined differently in extant literatures. In this paper, we adopt the straightforward definition specified in Lamond et al. (2009), that resilience connotes the ability to adapt positively to adversity.

Resilience scores have been demonstrated to be positively correlated with mental health and physical functioning of the elderly (Wagnild 2003; Hardy, Concato, and Gill 2002), as well as with self-rated successful aging (Lamond et al. 2009) in developed countries. Other studies have explored how resilience ameliorated the negative effect of adverse events on health and well-being. For instance, Windle, Woods, and Markland (2008) discovered that psychological resilience moderated the negative effect of chronic illness on subjective well-being among the elderly aged 60+ in England. Furthermore, several researchers have shown that resilient elderly people were more likely to experience positive emotions (Block and Block 1980; Masten 2001; Ong et al. 2006), which were found to promote health and longevity (Levy, Slade, and Kasl 2002; Giltay et al. 2004).

However, three aspects of the previous studies limited the development of research on resilience in aging. Above all, most of the prior studies were based on small samples, with especially limited numbers of the oldest-old subjects (Wagnild 2003; Lamond et al. 2009), which restricted the estimation efficiency. Second, many studies were cross-sectional (Hardy, Concato, and Gill 2002; Windle, Woods, and Markland 2008; Lamond et al. 2009) and few were based on longitudinal survey data. The crosssectional design could not provide time of death, which would be the key to exploring the association between resilience and survival. Third, almost all previous studies on this topic dealt with developed countries. However, the elderly populations in developing countries such as China, South Korea, India, and Mexico are increasing at a much faster rate and on a much larger scale than that in the developed countries (U.N. 2005). Our current study tried to make contributions in these three aspects to enhance research on resilience in aging.

\section{Data and measurements}

The data used in this paper were from the Chinese Longitudinal Healthy Longevity Survey (CLHLS). The CLHLS was carried out in 1998, 2000, 2002, 2005 and 20082009 in a randomly selected half of the counties, smaller cities at county level and districts under the large cities at prefecture or provincial level in 22 Chinese provinces, covering $85 \%$ of the total population (Zeng et al. 2008). The 1998 baseline and the 
2000 follow-up waves interviewed the oldest-old aged 80+ only; since the 2002 wave, younger elderly individuals, aged 65-79, were also included in the sample.

This study was based on the 2002-2005 longitudinal sample to explore the impact of resilience on survival among the elderly aged $65+$ over a 3 -year interval. The main advantage of applying a longitudinal dataset in this study is to learn about the influence of the resilience on mortality among the elderly who participated in 2002 survey, while controlling for various confounding factors including initial health status. We excluded those who were lost to follow-up in the 2005 survey (11.9\% of the initial sample) and the 61 deceased who had missing information on the time of death. ${ }^{3}$ The final sample size in this study was 13,800 elderly people, consisting of 5,896 men (42.72\%) and 7,904 women $(57.28 \%)$.

As CLHLS was a demographic survey rather than a specific psychological study, we did not have as many indicators as the resilience scale typically used in the psychological studies, such as the Connor-Davidson Resilience Scale (CD-RISC) proposed by Connor and Davidson (2003). Furthermore, considering that few Chinese elderly people were Christians, and all of our subjects were not formally employed, the indicators such as "sometimes fate or God can help", "you work to attain your goals" and "you prefer to take the lead in problem solving", etc. in CD-RISC were not relevant in our application. Thus, we selected 7 available items in CLHLS to measure resilience (See Table 1). The respondents were asked whether the item statements fit them (denoted as 1) or not (denoted as 0 ). As questions concerning items 1-4 and item 7 were regarding feelings about self, and were required to be answered by the elderly person $\mathrm{him} /$ herself in the survey, $13.5 \%$ of the respondents were unable to answer these questions due to poor cognitive capacity. Simply excluding these cases might lead to sampling bias. Thus we conducted multiple imputations for the missing values of these five resilience items based on the respondents' age, gender, race, education, physical and mental health measured by activities of daily living (ADL) and the Mini-Mental State Examination (MMSE) (Royston 2005). The total resilience scores ranged from 0 to 7 , with higher scores reflecting greater resilience.

\footnotetext{
${ }^{3} \mathrm{Gu}$ and Zeng (2004) conducted careful evaluation and suggested that sample attrition in CLHLS did not
} yield significant bias. 
Shen \& Zeng: The association between resilience and survival among Chinese elderly

Table 1: Measures of resilience: statements concerning self-evaluated resilience

\begin{tabular}{llcc}
\hline Items & Respondents were asked whether the statements fit with them & Yes & No \\
\hline Item 1 & I don't feel the older I get, the more useless I am & 4,558 & 9,242 \\
& & $(33.03)$ & $(66.97)$ \\
Item 2 & I always look on the bright side of things & 13,189 & 611 \\
& & $(95.57)$ & $(4.43)$ \\
Item 3 & I don't often feel fearful or anxious & 10,425 & 3,375 \\
& & $(75.54)$ & $(24.46)$ \\
Item 4 & I don't often feel lonely or isolated & 9,425 & 4,375 \\
& & $(68.30)$ & $(31.70)$ \\
Item 5 & I talk frequently to family members or friends in daily life & 12,463 & 1,337 \\
& & $(90.31)$ & $(9.69)$ \\
Item 6 & When I have problems, I can turn to my family or friends for & 12,873 & 927 \\
& help & $(93.28)$ & $(6.72)$ \\
Item 7 & I can make my own decisions concerning my personal affairs & 11,794 & 2,006 \\
& & $(85.46)$ & $(14.54)$ \\
\hline
\end{tabular}

Note: (1) Percentages are presented in parentheses.

As shown in Table 2, age, race (Han or minority), current residence (urban or rural), primary occupation before age 60 (non-manual job or manual job), education (literate or illiterate), and marital status (currently married or not) were included as socio-demographic controls. Because the follow-up mortality risk and resilience were both correlated with the initial health status, we further controlled for physical and mental health status in 2002 (see Table 2). Physical health was measured by ADL, consisting of eating, dressing, moving around the residence, using the toilet, bathing and continence. If the individual could complete all six activities without another's assistance, he/she was classified as "ADL independent"; if the individual needed help in at least one activity, he/she was classified as "ADL dependent." Mental health was measured by the MMSE, which included 24 items regarding orientation, registration, attention, calculation, recall and language, with a total score ranging from 0 to 30 . We used the same cutoff as the MMSE international standard to define a total score $\geq 24$ as "normal mental health" and a score $<24$ as "impaired mental health." 
Table 2: Descriptive statistics of the potentially confounding variables

\begin{tabular}{|c|c|c|c|c|c|}
\hline Confounding variables & Number & Percent & Confounding Variables & Number & Percent \\
\hline Socio-demographic characteristics & & & Primary occupation before age 60 & & \\
\hline Mean age & 86.40 & --- & Non-manual job & 1,110 & 8.04 \\
\hline Gender & & & Manual job & 12,690 & 91.96 \\
\hline Male & 5,896 & 42.72 & Marital status & & \\
\hline Female & 7,904 & 57.28 & Currently married & 4,081 & 29.57 \\
\hline Race & & & Currently not-married & 9,719 & 70.43 \\
\hline Han & 12,956 & 93.88 & Initial health status & & \\
\hline Minority & 844 & 6.12 & Activities of daily living & & \\
\hline Current residence & & & Independent & 9,697 & 70.27 \\
\hline Urban & 5,941 & 43.05 & Dependent & 4,103 & 29.73 \\
\hline Rural & 7,859 & 56.95 & MMSE & & \\
\hline Education & & & Good & 8,160 & 59.13 \\
\hline Literate & 8,637 & 62.59 & Impaired & 5,640 & 40.87 \\
\hline Illiterate & 5,163 & 37.41 & & & \\
\hline
\end{tabular}

Note: Variables are measured at the 2002 interview.

\section{Methods}

We conducted item-total correlations to test the internal consistency of the resilience scale as well as principle component analysis to assess its factor composition. We estimated Cox proportional hazards regression models controlling for the potential confounding variable to explore the association between resilience and survival of the elderly. Survival time from the 2002 interview to death (for those died) or to the 2005 interview (for those who survived who were considered as surveyed) was measured in months. We included the common factors of the resilience scale and the total score of resilience separately, to examine the impact of each factor and the overall effect of resilience. To better understand how the impact of resilience on mortality was moderated by confounding variables, we adopted a step by step approach.

\section{Results}

The item-total correlations ranged from 0.31 to 0.68 , implying that none of the 7 items should be dropped from the resilience scale (Field 2005). Principle component analysis generated 3 factors with eigenvalues $\geq 1$. These 3 factors could be interpreted as follows: Factor 1 contains 3 items reflecting self-approval, calmness and the social connection; Factor 2 contains 3 items reflecting close relationship with family and friends; Factor 3 contains 2 items reflecting optimism and control of own life (Table 3). 
Shen \& Zeng: The association between resilience and survival among Chinese elderly

Table 3: Factors and factor loading of the 7-item resilience scale

\begin{tabular}{|c|c|c|c|c|}
\hline Item & Factors and item statements & Eigenvalue & $\begin{array}{c}\text { Variance } \\
\text { explained (\%) }\end{array}$ & $\begin{array}{l}\text { Factor } \\
\text { loading }\end{array}$ \\
\hline \multicolumn{2}{|r|}{ Factor 1: self-approval, calmness and no loneliness } & 1.65 & $23.6 \%$ & \\
\hline 1 & I don't feel the older I get, the more useless I am & - & - & 0.61 \\
\hline 3 & I don't often feel fearful or anxious & - & - & 0.77 \\
\hline 4 & I don't often feel lonely or isolated & & & 0.79 \\
\hline \multicolumn{2}{|c|}{ Factor 2: close relationship with family and friends } & 1.33 & $19.0 \%$ & \\
\hline 5 & I talk frequently to family members or friends in daily life & - & - & 0.79 \\
\hline 6 & when I have problems, I can turn to my family or friends for help & - & - & 0.79 \\
\hline \multicolumn{2}{|c|}{ Factor 3: optimism and control of own life } & 1.05 & $15.0 \%$ & \\
\hline 2 & I always look on the bright side of things & - & - & 0.45 \\
\hline 7 & I can make my own decisions concerning my personal affairs & - & - & 0.87 \\
\hline
\end{tabular}

The estimates in Tables 4 showed that, without controlling for any confounding factors, the elderly who were more self-approving, calm and sociable had a $14 \%$ lower mortality risk (Model 1). The effect was ameliorated after adjusting for sociodemographic characteristics and initial health status (Model 2 and 3), but remained significant at the $\mathrm{P}<0.01$ level. Close relationship with family and friends significantly reduced the mortality risk by $13.5 \%$ (Model 1 ). After socio-demographic characteristics and initial health status were added to the model (Model 2 and 3), intimate relationship with family and friends reduced the mortality risk by $4.0-7.0 \%$, and both estimates were highly significant. However, optimism and control of own life had no significant impact on mortality risk with and without controlling for other covariates (Model 1-3).

Table 4: Hazard ratios of the effects of 3 resilience factors on mortality risk

\begin{tabular}{|c|c|c|c|}
\hline & Model 1 & Model 2 & Model 3 \\
\hline \multicolumn{4}{|l|}{ Resilience Measurements } \\
\hline $\begin{array}{l}\text { Factor1: self-approval, calmness and no loneliness } \\
\text { (Containing item 1, } 3 \text { and } 4 \text { ) }\end{array}$ & $0.860^{\star \star \star}$ & $0.905^{\star \star \star}$ & $0.942^{\star * *}$ \\
\hline $\begin{array}{l}\text { Factor2 (close relationship with family and friends) } \\
\text { (Containing item } 5 \text { and } 6 \text { ) }\end{array}$ & $0.865^{\star \star \star}$ & $0.930^{\star * *}$ & $0.960^{\star * *}$ \\
\hline $\begin{array}{l}\text { Factor3 (optimism and control of own life) } \\
\quad \text { (Containing item } 2 \text { and } 7 \text { ) }\end{array}$ & 1.022 & 1.016 & 1.007 \\
\hline \multicolumn{4}{|l|}{ Socio-demographic characteristics } \\
\hline Age & & $1.072^{* \star *}$ & $1.055^{\star \star *}$ \\
\hline Male (Female) & & $1.277^{\star \star \star}$ & $1.377^{\star \star \star}$ \\
\hline Han (Minority) & & $1.174^{\star \star \star}$ & 1.058 \\
\hline Urban (Rural) & & 0.989 & 0.979 \\
\hline Literate (Illiterate) & & 1.011 & 1.049 \\
\hline Non-manual job (Manual job) & & $0.872^{* *}$ & $0.900^{*}$ \\
\hline $\begin{array}{l}\text { Currently married (Divorced, widowed, never married) } \\
\text { Initial health status }\end{array}$ & \multicolumn{2}{|c|}{ Initial health status } & $0.761^{\star \star \star}$ \\
\hline$\overline{\text { Independent ADL (Dependent) }}$ & & & $0.611^{\star \star \star}$ \\
\hline Good MMSE (Impaired) & & & $0.667^{\star \star \star}$ \\
\hline Number of observations & 13,800 & 13,800 & 13,800 \\
\hline
\end{tabular}

Notes: (1) The categories indicated in the parentheses are reference groups; $(2){ }^{*} p<0.1 ;{ }^{* *} p<0.05 ;{ }^{* *} p<0.01$. 
As shown in the Model 1 in Table 5, without controlling for any covariates, the elderly with a high total resilience score $(\geq 6)$ were faced with $31.5 \%$ lower mortality risk, as compared to those with a lower resilience score $(<6)$. After adjusting for various covariates including physical and mental health, higher resilience reduced mortality risk at old ages by $9.2 \%$ and the estimate was still highly significant (Model 3 in Table 5). It was clear that a large part of the effect of resilience was moderated by sociodemographic characteristics and initial health status.

\section{Table 5: Hazard ratios of the effects of total resilience scores on mortality risk}

\begin{tabular}{|c|c|c|c|c|c|}
\hline & $\begin{array}{c}\text { Model } 1 \\
\text { (All elders) }\end{array}$ & $\begin{array}{c}\text { Model } 2 \\
\text { (All elders) }\end{array}$ & $\begin{array}{c}\text { Model } 3 \\
\text { (All elders) }\end{array}$ & $\begin{array}{c}\text { Model } 4 \\
\text { (Young-old) }\end{array}$ & $\begin{array}{c}\text { Model } 5 \\
\text { (Oldest-old) }\end{array}$ \\
\hline \multicolumn{6}{|l|}{ Total resilience score } \\
\hline$>=6(<6)$ & $0.685^{\star \star \star}$ & $0.827^{\star \star *}$ & $0.908^{\star \star *}$ & $0.831^{\star * *}$ & $0.930^{\star *}$ \\
\hline Socio-demographic characteristics & & & & $1.077^{\star * *}$ & $1.040^{\star \star \star}$ \\
\hline Age & & $1.072^{* * *}$ & $1.054^{\star \star \star}$ & $1.310^{* * *}$ & $1.332^{\star \star \star}$ \\
\hline Male (Female) & & $1.281^{\star \star *}$ & $1.380^{\star \star *}$ & 0.887 & $1.113^{*}$ \\
\hline Han (Minority) & & $1.199^{\star \star \star}$ & 1.068 & $0.892^{*}$ & 0.985 \\
\hline Urban (Rural) & & 0.993 & 0.98 & 1.122 & 1.03 \\
\hline Literate (Illiterate) & & 1.008 & 1.049 & 0.924 & 0.906 \\
\hline Non-manual job & & $0.877^{* *}$ & 0.902 & $0.817^{* * *}$ & $0.802^{\star \star \star}$ \\
\hline \multicolumn{6}{|l|}{ (Manual job) } \\
\hline Currently married (Currently not-married) & & $0.757^{* * *}$ & $0.755^{\star \star \star}$ & $0.465^{\star * *}$ & $0.630^{\star * *}$ \\
\hline Initial health status & & & & $0.546^{\star \star *}$ & $0.695^{\star \star \star}$ \\
\hline ADL Independent & & & $0.608^{\star \star \star}$ & & \\
\hline \multicolumn{6}{|l|}{ (Dependent) } \\
\hline Good MMSE (Impaired) & & & $0.659^{\star \star \star}$ & & \\
\hline Number of observations & 13,800 & 13,800 & 13,800 & 5,990 & 7,810 \\
\hline
\end{tabular}

Notes: the same as in Table 4

In order to explore differences in relationship between resilience and survival among different age ranges, we further conducted survival analyses among the youngold aged 65-84 and oldest-old aged 85+ separately, while also controlling for singleyear-age (Model 4 and 5 in Table 5). As compared to the young-old, the positive effect of high resilience on mortality was somewhat smaller among the oldest-old, and it was highly significant among both the young-old and oldest-old $(\mathrm{P}<0.01)$.

\section{Discussion and conclusions}

The present study was unique as it explored the association between resilience and longevity at old ages based on the unique longitudinal data with a sufficiently large subsample of the oldest-old in a developing country. Survival analyses showed that the total resilience score and most factors of the resilience scale had significantly positive 
impacts on longevity of the elderly, after controlling for socio-demographic characteristics and initial health status. The effect of resilience on survival among the young-old was somewhat larger than that among the oldest-old.

Although to our knowledge, few published studies have explored the relationship between resilience and survival, previous studies obtained comparable findings that resilient elderly have better mental health and physical function in developed countries (Wagnild 2003; Hardy, Concato, and Gill 2002). Resilience is considered as an important attribute in recovery from illness and other stressful event (Hardy, Concato, and Gill 2002; Lamond et al. 2009). When individuals reach advanced ages, accumulated negative conditions throughout the long process of aging, such as health deterioration and the loss of loved family members, represent serious challenges. The elderly of better resilience may have stronger capacity and potential for dealing successfully with constraints and adversity (Jopp and Rott 2006) to gain better health and longevity. The findings from the present study are in general consistent with the findings from the western world, which indicates that resilience performs as a source of protection for the elderly in both developing and developed countries.

Why was resilience positively associated with survival at old ages in China? One possible explanation was that resilience was positively correlated with better health, and better health lowered the mortality risk. This hypothesis was supported through our survival analyses, which showed that the effects of each resilience factor as well as the total resilience score on mortality risk shrank substantially after variables of initial health status entered the model. Prior investigations also lent support to this explanation (Wagnild 2003; Lamond et al. 2009; Ong et al. 2006). However, our analysis demonstrated that, even after controlling for the initial health status, the protective effects of the total resilience score and most of the resilience factors on mortality risk still remained significant. These results indicated that resilience may have independent effects on mortality risk.

The findings presented in this paper should be interpreted with caution given the limitations of our study. First, as the CLHLS was a demographic survey focusing on demographic characteristics, socio-economic status, life style, health status and mortality risk of the elderly, we did not have as many resilience indicators as specific psychological surveys did. Second, we have only examined the association between resilience and mortality, but we were unable to explore the causal relationship and the detailed mechanisms on how resilience works, due to data limitations. More detailed data and advanced methods such as instrumental analysis are called for to explore the causal relationship and the mechanisms in further studies.

In conclusion, the present study provided evidence to support the conclusion that better resilience was associated with reduced mortality risk among the young-old and oldest-old in a developing country, China. Policies aiming to promote resilience such as 
organizing group activities and encouraging individual expression (Waaktaar et al. 2004) are likely to have long-reaching effects on longevity of the elderly.

\section{Acknowledgements}

This study is part of the CLHLS project funded by NIA/NIH (R01 AG023627-01), China Natural Science Foundation (70533010), UNFPA, China Social Sciences Foundation, and Hong Kong Research Grants Council. 


\section{References}

Block, J.H., and Block, J. (1980). The role of ego-control and ego-resiliency in the origination of behavior. In: Collins, W.A. (ed.). The Minnesota Symposia on Child Psychology (Vol. 13, pp. 39-101). Hillsdale, NJ: Erlbaum.

Connor, K.M. and Davidson, J.R. (2003). Development of a new resilience scale: the Connor-Davidson Resilience Scale (CD-RISC). Depression and Anxiety 18: 76-82. doi:10.1002/da.10113.

Gu, D. and Zeng, Y. (2004). Data Quality Assessment of the CLHLS 1998, 2000, and 2002 Waves. In Zeng, Y., Liu, Y., Zhang, C., and Xiao, Z. (eds.) Analyses of the Determinants of Healthy Longevity. Beijing: Peking University Press: 4-22.

Field, A. (2005). Discovering statistics using SPSS. $2^{\text {nd }}$ ed. London: Sage.

Giltay, E.J., Geleijnse, J.M., Zitman, F.G., Hoekstra, T., and Schouten, E.G. (2004). Dispositional optimism and all-cause and cardiovascular mortality in a prospective cohort of elderly Dutch men and women. Archives of General Psychiatry 61: 1126-1135. doi:10.1001/archpsyc.61.11.1126.

Hardy, S.E., Concato, J., and Gill, T.M. (2002). Stressful life events among communityliving older persons. Journal of General Internal Medicine 17: 832-838. doi:10.1046/j.1525-1497.2002.20105.x.

Jopp, D. and Rott, C. (2006). Adaptation in very old age: exploring the role of resources, beliefs, and attitudes for centenarians' happiness. Psychology and Aging 21(2) 266-280. doi:10.1037/0882-7974.21.2.266.

Lamond, A.J., Depp, C.A., Allison, M., Langer, R., Reichstadt, J., Moore, D. J., Golshan, S., Ganiats, T. G., and Jeste, D. V. (2009). Measurement and predictors of resilience among community-dwelling older women. Journal of Psychiatric Research 43: 148-154. doi:10.1016/j.jpsychires.2008.03.007.

Levy, B.R., Slade, M.D., and Kasl, S.V. (2002). Longitudinal benefit of positive self perceptions of aging on functional health. Journals of Gerontology Series BPsychological Sciences and Social Sciences 57: 409-417.

Masten, A.S. (2001). Ordinary magic: Resilience processes in development. American Psychologist 56: 227-238. doi:10.1037/0003-066X.56.3.227.

Ong, A.D., Bergeman, C.S., Bisconti, T.L., and Wallace, K.A. (2006). Psychological resilience, positive emotions and stressful adaptation to stress in later life. 
Journal of Personality and Social Psychology 91(4): 730-749. doi:10.1037/0022-3514.91.4.730.

Royston, P. (2005). Multiple imputation of missing values: update. The Stata Journal $5(2) 1-14$.

United Nations, Population Division (2005). World population prospects: The 2004 revision. New York.

Wagnild, G. (2003). Resilience and successful aging: Comparison among low and high income older adults. Journal of Gerontology Nursing 29: 42-49.

Waaktaar, T., Christie, H.J., Borge, A.I.H., and Torgersen, S. (2004). How can young people's resilience be enhanced? Experiences from a clinical intervention project. Clinical Child Psychology and Psychiatry 9(2): 167-183. doi:10.1177/1359104504041917.

Windle, G., Woods, R., and Markland, D. (2008). The effect of psychological resilience on the relationship between chronic illness and subjective well-being. The Gerontologist 48, 179.

Zeng, Y., Poston, D., Ashbaugh Vlosky, D., and Gu, D. (eds.) (2008). Healthy Longevity in China: Demographic, Socioeconomic, and Psychological Dimensions. Dordrecht: Springer Publisher. 
Shen \& Zeng: The association between resilience and survival among Chinese elderly 